Artigos

\title{
Dispositivos de monitoramento e a máquina penal: separar a boa circulação da má
}

Ricardo Urquizas Campello'

Resumo: $\mathrm{O}$ artigo analisa a aplicação dos dispositivos de monitoramento eletrônico de presos no Brasil, relacionando tais práticas ao funcionamento do sistema penal de maneira mais ampla. Investiga-se as transformações e redimensionamentos operados por meio da instalação de novos mecanismos de controle penal, evidenciando as conexões e relações de complementaridade estabelecidas entre o aparato carcerário e as tecnologias de rastreamento. $\mathrm{O}$ texto relaciona as noções de dispositivo (Foucault, 1979) e máquina (Deleuze; Guattari, 2014), voltadas à análise do sistema penal, em processo de permanente metamorfose.

Palavras-chave: Dispositivo; máquina; monitoramento; governamentalidade.

Monitoring dispositifs and the penal machine - separate the good circulation from the bad

Abstract: The paper analyses the enforcement of the electronic monitoring devices in Brazil, relating it with the broader functioning of criminal justice. The transformations and resizing operated by new penal control mechanisms are investigated, showing the connections and complementary relations between the prison apparatus and tracking technologies. The text lists the dispositif and machine concepts, focused on the analysis of the penal system, in constant metamorphosis process.

1 Programa de Pós-Graduação em Sociologia da Universidade de São Paulo (PPGS-USP) - São Paulo Brasil - campello.ricardo@gmail.com. 
Keywords: Dispositif; machine; monitoring; governmentality.

- É um aparelho singular - disse o oficial ao explorador, percorrendo com um olhar até certo ponto de admiração o aparelho que ele no entanto conhecia bem (Kafka, 1998: 29).

O SAC24 (Sistema de Acompanhamento de Custódia 24 horas) baseia-se em uma "solução completa de hardware e software para monitoramento eletrônico de sentenciados" concebida e desenvolvida pela Spacecom Monitoramentos Ltda., em parceria com o Instituto de Tecnologia para o Desenvolvimento (LACTEC) e o Conselho Nacional de Desenvolvimento Científico e Tecnológico (CNPq). O mecanismo é formado pela interconexão entre a rede de satélites que compõe o Sistema de Posicionamento Global (GPS), uma Central de Monitoramento e uma tornozeleira eletrônica.

O GPS permite a localização georreferenciada, em tempo real, do transmissor portátil instalado na tornozeleira, revestida por fibra ótica para detecção de possíveis violações ou rompimentos. O equipamento acoplado ao corpo do indivíduo monitorado envia as informações criptografadas a respeito de seu posicionamento à Central de Monitoramento através da rede de telefonia celular GPRS, disponibilizando-as via interface Web ao software da Spacecom. A criptografia codifica as informações emitidas de maneira que apenas o seu receptor possa ler os dados fornecidos pelo aparelho móvel, prevenindo assim interceptações indevidas.

De acordo com a empresa, "o SAC24 possui material confiável e resistente, à prova d'água e de fácil instalação". O sistema permite a criação de "áreas de controle para restrições comportamentais", nas quais a pessoa rastreada deve permanecer nos horários estipulados em decisão judicial. Caso ele penetre uma zona de exclusão ou rompa o lacre da tornozeleira, a Central de Monitoramento é imediatamente alertada por meio de um alarme online, informando a numeração do equipamento à Coordenadoria Regional de Unidades Prisionais, que deve acionar a Polícia Militar para que seja feita a captura do preso.

\section{"uma história das técnicas..."}

Em Gilles Deleuze e Félix Guattari, "uma máquina é como um conjunto de pontas que se inserem no agenciamento em vias de desterritorialização, para

\footnotetext{
2 Spacecom. Sistema SAC24 - Apresentação. Disponível em: <http://spacecom.com.br/>. Acesso em: 10 jan. 2016. 
traçar suas variações e mutações" (Deleuze; Guattari, 1997: 146). Um ordenador de múltiplos dispositivos que reorganizam sua relação forma-função.

Este artigo trata de uma máquina em particular: a máquina penal. Mais precisamente, analisa-se alguns dos aspectos de formação de um dispositivo específico e consideravelmente novo que vem compor a máquina, traçando suas variações e mutações. Um complexo técnico-penal atravessado por leis, programas, discursos, instituições e enunciações que descrevem sua heterogeneidade e reconfiguram um diagrama. Uma das pontas de uma máquina em expansão.

$\mathrm{O}$ chamado controle telemático ${ }^{4}$ de presos foi legalmente autorizado no Brasil no ano de 2010 a partir de uma edificação legislativa que conjugou o legal e o ilegal, descortinando as fábulas e paradoxos que constituem o aparelhamento jurídico. ${ }^{5}$ Atualmente, a medida é aplicada em quase 20 mil pessoas no país, com tendência à multiplicação, de acordo com operadores da justiça criminal.

Pretende-se aqui investigar algumas implicações da emergência de um dispositivo de monitoramento, relacionado a um projeto securitário que nivela concepções díspares e sinaliza transformações na mecânica punitiva. Interessa analisar a formação de uma nova tecnologia capaz de redimensionar as práticas vinculadas ao poder de punir, inserindo novas táticas no seio de uma estratégia geral.

Novos arranjos se estabelecem, redimensionando a capacidade de vigilância do aparato estatal em monitoramentos descentralizados, impulsionados pelos agenciamentos de um mercado em expansão: o mercado do castigo. Novas agências se formam, novas práticas se anunciam, rearticulando os velhos métodos e fixando, contudo, sua manutenção.

Desse modo, propõe-se a contribuir de algum modo em uma história das técnicas penais, tendo em vista que a técnica implica necessariamente em uma forma específica de exercício político (Foucault, 1987). Persegue-se os deslocamentos da atual economia política do controle que atravessa muros e refaz triagens, reposicionando os horizontes ampliados de uma vasta colônia penal.

\section{Demandas}

A entrada do Século XXI foi marcada por um extraordinário incremento da população trancada nas unidades prisionais espalhadas pelo Brasil. Os dados oficiais indicam que entre 1995 e 2000, a quantidade de pessoas presas no país

4 A comunicação telemática é formada pela interconexão entre os recursos disponibilizados pela engenharia eletrônica, a informática e as telecomunicações.

5 A respeito da construção ilegal das leis que regulamentam a aplicação do monitoramento eletrônico no Brasil, ver: Circulações governadas (Campello, 2014). 
cresceu a uma taxa de $18 \%$. Entre 2000 e 2005, esse índice chegou a 106\%. Se no ano 2000 havia 100 presos para cada 100 mil habitantes no Brasil, em 2005, esse número praticamente dobrou, atingindo 194 presos para cada 100 mil habitantes. Os últimos dados, publicados em junho de 2014, apontam para uma taxa de mais de 299 presos para cada 100 mil habitantes, perfazendo um total de 607.731 indivíduos encarcerados no país (Brasil, 2014).

Unidades superlotadas, corpos amontoados em celas minúsculas, condições deploráveis de sobrevivência no cárcere, espancamentos, tortura e fortalecimento das chamadas "facções criminosas" compõem o calamitoso cenário prisional brasileiro durante as primeiras décadas do século. O suposto propósito ressocializador atribuído à pena de detenção revelou-se fictício, produzindo efeitos de realidade que nem mesmo a ficção poderia de conceber. Altos índices de reincidência e a formação de um circuito econômico-político de ilegalismos que transpassa os muros carcerários constituem a prisão como uma fantástica usina da delinquência. Incapaz de converter seus criminosos em sujeitos pacificados, 0 aparato carcerário parece ser fomentado pela violência que ele mesmo incita.

É nesse contexto que emergem as campanhas pela implementação do monitoramento eletrônico no Brasil, como forma de controle penal a céu aberto. Em 2007, iniciaram-se as primeiras experiências de supervisão telemática de presos no país, realizadas por magistrados, empresários da indústria da segurança e secretarias de administração penitenciária e justiça criminal, concomitantemente aos primeiros projetos de lei que versavam sobre o tema.

De início, é possível detectar três principais argumentos que mobilizaram a introdução dos dispositivos de monitoramento no país. Por um lado, programas voltados à ampliação da aplicação de alternativas penais fomentavam práticas de penalização em meio aberto como forma de solução humanitária para a crise penitenciária. Data também de 2007, por exemplo, a criação da Comissão Nacional de Apoio às Penas e Medidas Alternativas (CONAPA) como órgão integrante do Departamento Penitenciário Nacional (DEPEN).

Nesse sentido, não raros foram os argumentos que imbuíam o monitoramento eletrônico de um potencial ressocializador, quando aplicado em substituição ao cárcere. $\mathrm{O}$ texto do Projeto de Lei do Senado n. 175, elaborado pelo Senador Magno Malta (PR-ES), também em 2007, afirmava a capacidade do controle telemático de promover "a melhora da inserção dos condenados, evitando-se a ruptura dos laços familiares e a perda do emprego, a luta contra a superpopulação carcerária e, além do mais, economia de recursos" (Brasil, 2007).

Por outro lado, a importação e adaptação de doutrinas conservadoras no âmbito da justiça criminal e de programas de segurança pública pautados pelo 
lema do "combate ao crime", oriundos principalmente dos Estados Unidos, contribuíram significativamente para a introdução dos mecanismos de rastreamento de presos no Brasil. Movimentos estes que impulsionaram o crescimento exorbitante da população carcerária no país, incitaram a criação de novas tipologias penais em meio aberto, além de terem concebido sistemas informatizados de monitoramento do espaço urbano como estratégia central de enfrentamento à criminalidade. A exemplo disso, pode-se citar o programa policial de Tolerância Zero, deflagrado a partir das décadas de 1970 e 1980 nos EUA e exportado para diversos países, dentre eles o Brasil. ${ }^{6}$ Mecanismos baseados em técnicas computoinformacionais e de modelos renovados de gestão das forças de segurança pública constituem algumas das marcas do Tolerância Zero admiradas por líderes políticos e chefes de segurança em todo o planeta.

Como terceira linha de força, atravessando e abarcando as duas primeiras, a iniciativa privada apresentava, por sua vez, as vantagens do monitoramento, lançando mão de uma argumentação econômico-política, de prestação de serviço público que se baseava tanto na hipótese da reabilitação, como no favorecimento ao corte de gastos que seus produtos propiciariam ao Estado: "O sistema resulta em maior economia para o Estado e uma melhor possibilidade de reabilitação do indivíduo. Trata-se do único sistema nesta área com tecnologia nacional e com características voltadas à realidade brasileira", anunciava a empresa Spacecom em sua página na internet. ${ }^{7}$

De políticos conservadores a exigências humanitárias, abarcando os ímpetos de um mercado em florescimento, orquestraram-se os enunciados que justificavam a aprovação da medida. Um jogo de ofertas e demandas que configurou uma determinada composição de discursos proferidos em frentes que se modulavam, constituindo aquilo que Deleuze e Guattari (2014) designam de agenciamento coletivo de enunciação, imanente ao conteúdo político enunciado e componente necessário de um dispositivo em emergência.

No dia 15 de junho de 2010, o controle eletrônico de condenados seria legalmente autorizado no país por meio da Lei Federal n. 12.258, atendendo a demandas heterogêneas que oscilavam entre o conservadorismo punitivo, o empreendedorismo do setor privado e o reformismo humanitário.

6 Atrelado ao Tolerância Zero, o movimento de justiça criminal denominado Lei e Ordem também pode ser considerado uma das forças que favoreceram a invenção de novos tipos penais, além do endurecimento dos controles sobre aqueles que cumprem medida em meio aberto.

7 Spacecom. Sistema SAC24 - Apresentação. Disponível em: <http://www.spacecom.com.br/?s=mon>. Acesso em: 16 mar. 2014 . 


\section{Anexos virtuais}

Michel Foucault utiliza a noção de dispositivo como uma composição de elementos que processam determinados efeitos de poder a partir de uma dupla dimensão: de um lado, dimensão micropolítica, irredutível ao aparelho de Estado e organizadora de uma multiplicidade difusa; de outro, dimensão diagramática, imanente ao campo social.

Um dispositivo, em Foucault, é formado pela interconexão de projetos, programas, doutrinas, regramentos. $\mathrm{O}$ autor situa:

Através deste termo tento demarcar, em primeiro lugar, um conjunto decididamente heterogêneo que engloba discursos, instituições, organizações arquitetônicas, decisões regulamentares, leis, medidas administrativas, enunciados científicos, proposições filosóficas, morais, filantrópicas. Em suma, o dito e o não dito são os elementos do dispositivo. $\mathrm{O}$ dispositivo é a rede que se pode estabelecer entre estes elementos. Em segundo lugar, gostaria de demarcar a natureza da relação que pode existir entre estes elementos heterogêneos. Sendo assim, tal discurso pode aparecer como um programa de uma instituição ou, ao contrário, como elemento que permite justificar e mascarar uma prática que permanece muda (Foucault, 1979: 244).

A emergência do monitoramento eletrônico ligava-se às tendências penalógicas e criminológicas provenientes principalmente dos Estados Unidos, fazendo confluírem, tal como no Brasil, paradigmas variados. ${ }^{8}$ Campanhas pela modernização do sistema de justiça criminal, programas de segurança pública baseados no zoneamento georreferencial do espaço urbano, projetos de controle do crime a baixos custos e a busca por mecanismos mais eficientes de reabilitação do delinquente permearam o imaginário criminológico estadunidense e suas respectivas instituições durante a segunda metade do Século XX. Conectados a um equipamento específico, todo um conjunto de enunciados e um complexo de aparelhos adjacentes se constituem.

A medida inseria-se em um programa de superação da crise penitenciária que atravessava fronteiras, respondendo a exigências ecléticas. Sua aplicação deveria substituir a prisão de criminosos considerados de "baixa periculosidade". No Brasil, a sanção da Lei Federal n. 12.258/2010 regulamentou a aplicação da medida, estabelecendo que nos casos de saída temporária no regime

8 A respeito da emergência do monitoramento eletrônico nos EUA e dos fundamentos teóricos que sustentaram sua emergência, ver Campello, 2015. 
semiaberto de cumprimento de pena, ou na determinação de prisão domiciliar, o juiz poderia definir a "fiscalização" por meio de "monitoração eletrônica" (Brasil, 2010, Art. 146-B).

Menos de um ano depois, em 4 de maio de 2011, as possibilidades de aplicação do rastreamento foram ampliadas para medidas preventivas, aplicadas antes da sentença condenatória, por meio da Lei Federal n. 12.403 (Brasil, 2011). O objetivo desta era permitir que se colocasse em liberdade monitorada parte do enorme contingente de pessoas submetidas a prisão processual no país sem que tenham sido condenadas.

Hoje, cerca de 18.172 pessoas já são monitoradas no Brasil, de acordo com o DEPEN. Destas, $88 \%$ são homens e $12 \%$ mulheres. O país possui centrais de monitoramento instaladas em 19 Unidades da Federação, sendo que em 17 delas os serviços encontram-se implementados e em 2 unidades estão em fase de testes. ${ }^{9}$ O estado de São Paulo lidera o ranking dos que mais monitoram, com 4.200 pessoas rastreadas, seguido por Minas Gerais, com 2.390, e Pernambuco, com 2.300 (Brasil, 2015).

Entretanto, o acompanhamento dos dados penitenciários indica que a medida não tem apresentado impactos no sentido de contribuir para a redução da quantidade de pessoas encarceradas, contrariando a argumentação daqueles que viam no controle eletrônico um mecanismo substituto ao cárcere. Se em junho de 2009 - cerca de um ano antes da promulgação da Lei Federal que instituiu o monitoramento - havia em torno de 248 presos por 100 mil habitantes no Brasil, em junho de 2014 essa taxa chegou a mais de 299 (Brasil, 2014).

Em relatório divulgado em dezembro de 2015 a respeito da "Política de Monitoração Eletrônica de Pessoas no Brasil", o DEPEN indica que a medida tem sido aplicada majoritariamente para a supervisão de prisão domiciliar nos regimes aberto ( $25,9 \%$ das aplicações) e semiaberto $(21,9 \%)$, ou para controle de trabalho externo no regime semiaberto $(19,9 \%)$. Ou seja, o dispositivo é utilizado prioritariamente em pessoas que já cumpririam pena em regime aberto ou semiaberto, sendo ínfima sua aplicação como forma de substituição à prisão preventiva, por exemplo $(8,4 \%)$.

9 A estruturação necessária para o monitoramento eletrônico já foi implementada nos estados do Acre, Alagoas, Amazonas, Ceará, Espírito Santo, Goiás, Maranhão, Mato Grosso, Minas Gerais, Pará, Paraná, Pernambuco, Piauí, Rio Grande do Sul, Rio de Janeiro, Rondônia e São Paulo. Em Santa Catarina e Sergipe os serviços estão em fase de testes. Bahia, Distrito Federal, Mato Grosso do Sul, Paraíba, Rio Grande do Norte e Roraima possuem projetos que visam a implementação do monitoramento. O estado do Amapá é o único que não possui planejamento para a implantação da medida (Brasil, 2015: 32). 
Diante disso, o relatório do DEPEN concluiu: “a monitoração eletrônica não vem se configurando como uma alternativa à prisão, mas como um instrumento aliado aos movimentos de controle social e de recrudescimento do poder punitivo" (Brasil, 2015: 50). Cinco anos após a regulamentação da medida, os operadores constatam os efeitos por ela mobilizados, relacionados à ampliação e à intensificação do controle penal no país.

Ampliação: a criação de medidas penais em meio aberto no Brasil, ao contrário de favorecer um suposto processo de desencarceramento, tem submetido indivíduos que cometeram pequenas infrações, cuja insignificância não justificaria a prisão, a uma supervisão penal além-muros, propiciando o que Loïc Wacquant (2001) chama de "expansão horizontal do sistema penal" - cresce a população monitorada concomitantemente ao crescimento da população encarcerada. Intensificação: o dispositivo de monitoramento confere um controle adicional, ininterrupto e georreferenciado sobre os deslocamentos de indivíduos em regimes aberto e semiaberto, sem, contudo, promover o anunciado processo de substituição ao cárcere.

Desejados ou não, os resultados apontam para as ligações que se estabelecem entre a tecnologia carcerária e as incipientes técnicas de monitoramento, delineando as relações complementares estabelecidas entre o dispositivo de monitoramento e o dispositivo carcerário. Ligações e complementos que fazem dilatarem-se os muros prisionais, reconfigurando o modelo panóptico, redimensionado em olhar móvel, pulverizado, sem centro e sem rosto. A máquina penal é atualizada e potencializada a partir de seus acoplamentos. O processo duplo de ampliação e intensificação do sistema penal se realiza mediante o controle dos corpos em circulação: não mais esquadrinhados, mas rastreados. Não mais adestrados, mas conduzidos. A mobilidade é uma armadilha.

Para Deleuze e Guattari,

Jamais uma máquina é simplesmente técnica. Ao contrário, ela só é técnica como máquina social, tomando homens e mulheres em suas engrenagens, ou, antes, tendo homens e mulheres dentre suas engrenagens, não menos que coisas, estruturas, metais, matérias. O que faz máquina, falando propriamente, são as conexões (Deleuze; Guattari, 2014: 147).

A análise genealógica empregada por Foucault indica a faculdade de instalação de novos dispositivos a partir das correlações estabelecidas com as técnicas predecessoras, ainda que evoquem a contradição do programa anterior. Descarta-se o paradigma de uma série progressiva na qual as técnicas punitivas 
se sucederiam fazendo desaparecerem os antigos métodos (Foucault, 2008b). Anexam-se novas engrenagens "ao lado da engrenagem precedente, indefinidamente, mesmo se essas engrenagens parecem se opor ou funcionar de maneira discordante" (Deleuze; Guattari, 2014: 148).

Inversamente, o já arcaico projeto de confinamento disciplinar se redefine e reorganiza diante dos novos agenciamentos que se engendram. A própria prisão parece ser marcada hoje menos por aspectos totalizantes do que por seus poros e extensões, perfurando os limites entre o dentro e o fora e denotando às ruas, aos guetos e às periferias das grandes cidades o caráter vigilante do interior carcerário. A multiplicidade de agentes e agências de monitoramento - câmeras, registros digitais, perfis biométricos e polícias de toda ordem - conferem às fraturas urbanas o seu ar prisional. As transmutações dos regimes de controle fazem-se a partir das diferentes conexões agenciadas entre corpos e técnicas.

\section{Deixar passar}

A ultrapassagem do modelo disciplinar é analisada nos estudos de Foucault a respeito das práticas de governamentalidade. $\mathrm{O}$ autor investiga a emergência de uma determinada orientação racional que introduz as dinâmicas de mercado em esferas jurídicas, políticas, sociais, subjetivas. O que o autor chama de governamentalidade neoliberal refere-se a uma racionalidade de governo que orienta as formas pelas quais se administra a conduta dos indivíduos a partir de cálculos de custo-eficiência, gerenciamento de riscos, projeções de utilidade, instrumentalizando dispositivos de segurança como técnicas de condução das condutas (Foucault, 2008; 2008b).

No âmbito penal, a superação dos modelos estáticos de castigo intra-muros remete à elaboração de mecanismos securitários, dirigidos pela aritmética política de gestão utilitária do crime e do criminoso. Para certos "tipos" de infratores, não se trata de buscar meios voltados à sua eliminação, mas de encontrar técnicas capazes de torná-los governáveis e, tanto quanto possível, extrair da atividade criminosa um determinado lucro, tal como das próprias políticas penais.

Assim como o crime, o castigo torna-se cada vez mais um negócio rentável, cuja expansão do mercado consumidor é condição infalível de sua manutenção e desenvolvimento. Revisitando o utilitarismo liberal, a racionalidade neoliberal de gestão do crime mobiliza práticas punitivas teorizadas por uma penalogia voltada à administração gerencial de populações e indivíduos considerados perigosos ou vulneráveis, concebendo práticas penais fundadas em projeções de custos, riscos, eficiência, lucro. 
Sem prescindir ao sequestro dos corpos, o poder de punir se reconfigura, concentrando-se em triá-los, conduzi-los, gerenciá-los, produzir uma determinada situação em que as circulações de indivíduos e populações se façam úteis, utilizáveis. As metamorfoses da máquina penal sinalizam formas de gerir as circulações, sem bloqueá-las, fazê-las fluir, favorecer os trânsitos por meio de um programa satisfatório de conexões, separando a circulação desejável da indesejável, a boa da má, maximizando a boa circulação e otimizando o controle da má (Idem).

A tecnologia penal que hoje se anexa ao isolamento disciplinar, bem como ao direito de morte, concentra-se em desobstruir passagens, reconduzir fluxos, escalonar o gerenciamento de liberdades, equacionando-as com segurança. $\mathrm{O}$ cálculo securitário toma a liberdade como bem de consumo, produzido a partir de práticas de governamentalidade e regulado como transação gradual de sua interdição. Ao lado das duras tecnologias de punição fundadas na extração do sangue ou no confinamento dos corpos, instalam-se barreiras móveis, maleáveis, penetráveis, cuja flexibilidade pode, no entanto, ser tão ou mais sufocante que a dureza das instituições prisionais, na medida em que a constrição deve ser incutida no próprio modo de ser e de pensar do criminoso, tornado agente racional, empreendedor de sua própria conduta, carcereiro de si mesmo.

É nesse ponto, portanto, que o diagrama securitário se espraia pelos ermos espaços do tecido social. Do criminoso ao capitalista, do intelectual ao chefe de Estado, da moderna mãe de família ao indigente-empreendedor carroceiro ou catador de lata, a lógica programática que visa o índice de equilíbrio liberdade-segurança torna-se transversal, atravessando os modos de existência. O neoliberalismo converte-se em um estilo de vida que avalia riscos, custos, danos e prognostica segurança, lucro, eficiência, projetando trajetos e itinerários seguros, pagando o preço pelos desvios desmedidos.

Da gestão institucional ao gerenciamento da vida privada, os dispositivos de monitoramento se generalizam. Das câmeras de segurança pulverizadas pelas ruas aos nanocomputadores de bolso portados por cada um. Do compartilhamento de dados no mundo virtual aos cartões de crédito do cidadão endividado. Dos bancos de registros genéticos de delinquentes ou psicóticos ao chip antisequestro implantado sob a derme da criança milionária.

Em meio às conexões, o ponto de incidência imediata e direta dos dispositivos de monitoramento continua sendo o corpo. É ele que constitui o alvo e meio de composição da multiplicidade de elementos que compõe as tecnologias securitárias. É nele que os enunciados se inscrevem, que as normas se fazem e que os protocolos se instalam. É ainda sobre o corpo que recaem a lei, a disciplina e os monitoramentos que compõem a máquina penal, processadora de uma colônia vasta e potencialmente ilimitada. 


\section{Referências}

BRASIL. Lei n. 12.403, de 4 de maio de 2011. Altera dispositivos do Decreto-Lei n. 3.689, de 3 de outubro de 1941 - Código de Processo Penal, relativos à prisão processual, fiança, liberdade provisória, demais medidas cautelares, e dá outras providências. Brasília: Congresso Nacional, 2011.

. Lei n. 12.258, de 15 de junho de 2010. Altera o Decreto-Lei n. 2.848, de 7 de dezembro de 1940 (Código Penal), e a Lei n. 7.210, de 11 de julho de 1984 (Lei de Execução Penal), para prever a possibilidade de utilização de equipamento de vigilância indireta pelo condenado nos casos em que especifica. Brasília: Congresso Nacional, 2010.

. Ministério da Justiça/Departamento Penitenciário Nacional. A implementação da política de monitoração eletrônica de pessoas no Brasil. Brasília, DEPEN, 2015.

. Ministério da Justiça/Departamento Penitenciário Nacional. Levantamento Nacional de Informações Penitenciárias. Brasília, DEPEN, 2014.

. Projeto de Lei n. 175 de 2007. Altera o Decreto-Lei n. 2.848, de 7 de dezembro de 1940 (Código Penal), e a Lei n. 7.210, de 11 de julho de 1984 (Lei de Execução Penal), para prever a possibilidade de utilização de equipamento de vigilância indireta pelo condenado nos casos em que especifica. Brasília: Senado Federal, 2007.

CAMPELLO, Ricardo Urquizas. Circulações governadas: o monitoramento eletrônico de presos no Brasil. Aurora: revista de arte, mídia e política. São Paulo: PUC-SP, v. 7, n. 19, p. 51-69, 2014.

. O monitoramento eletrônico de presos nos Estados Unidos: um trajeto genealógico. In. Revista Estudos de Sociologia. v. 1. Araraquara: UNESP/FCLR, 1996, pp. 75-92, 2015.

DELEUZE, Gilles. Foucault. Tradução de Claudia Sant’Anna Martins. São Paulo: Brasiliense, 2005.

; GUATTARI, Félix. Kafka: por uma literatura menor. Tradução de Cíntia Vieira da Silva, Belo Horizonte: Autêntica Editora, 2014.

. Mil platôs: capitalismo e esquizofrenia, vol. 4. Tradução de Suely Rolnik, São Paulo: Ed. 34, 1997

FOUCAULT, Michel. Microfísica do poder. Organização e tradução de Roberto Machado.

Rio de Janeiro: Edições Graal, 1979.

. Nascimento da biopolítica. Tradução de Eduardo Brandão. São Paulo: Martins Fontes, 2008

O sujeito e o poder. In: Hubert L. Dreyfus e Paul Rabinow (Orgs.). Michel Foucault. Uma Trajetória Filosófica. Para além do estruturalismo e da hermenêutica. Tradução 
de Vera Portocarrero e Gilda Gomes Carneiro. Rio de Janeiro: Forense Universitária, 2009, pp. 231-249.

. Segurança, Território, População. Tradução de Eduardo Brandão. São Paulo: Martins Fontes, 2008b.

Vigiar e punir: nascimento da prisão. Tradução de Raquel Ramalhete. Petrópolis: Vozes, 1987.

KAFKA, Franz. O veredicto e Na colônia penal. Tradução de Modesto Carone. São Paulo: Companhia das Letras, 1998.

WACQUANT, Loïc. As prisões da miséria. Tradução de André Telles. Rio de Janeiro: Jorge Zahar, 2001.

Recebido em 18/02/2016

Aprovado em 29/11/2016

\section{Como citar este artigo:}

CAMPELLO, Ricardo Urquizas. Dispositivos de monitoramento e a máquina penal: separar a boa circulação da má. Contemporânea - Revista de Sociologia da UFSCar, v. 7, n. 1, jan.- jun. 2017, pp. 211-222. 